\title{
Regulamentação da prostituição: polêmica e argumentação
}

\section{Edvania Gomes da Silva}

Docente da Universidade Estadual do Sudoeste da Bahia (UESB), Brasil. edvaniagsilva@gmail.com

\section{Lara Maria dos Santos Pires}

Mestranda do Programa de Pós Graduação em Linguística da Universidade Estadual do Sudoeste da Bahia (UESB), Brasil.

laramariapires@gmail.com

Resumo: Com base nos postulados da Análise do Discurso (AD), mais precisamente nos trabalhos de Dominique Maingueneau (2005 [1984], 2010) e Ruth Amossy (2017), investigamos, neste artigo, a relação que se estabelece entre os discursos contrários e favoráveis à regulamentação da prostituição como profissão. Para tanto, formulamos a hipótese de que tal relação é constitutivamente polêmica, pois há, nesse caso, a emergência de uma incompatibilidade constitutiva. Para verificar o funcionamento da referida relação, analisamos, nos textos do corpus, indícios linguísticos, que emergem com certa regularidade e que apontam para um funcionamento discursivo. Os resultados indicam que a polêmica estabelecida entre os dois posicionamentos estudados funciona como fonte de argumentos tanto para o posicionamento Proponente quanto para o Oponente, já que cada um deles constitui sua legitimidade com base na desqualificação do outro.

Palavras-chave: Interdiscurso. Polêmica. Argumentação. Regulamentação da prostituição.

Abstract: Based on the postulates of the Discourse Analysis (DA), more specifically on Dominique Maingueneau's (2005 [1984], 2010) and Ruth Amossy's (2017) works, we investigate, in this paper, the relationship that is established between the contrary and the favorable discourses to the prostitution regulation as a profession. For this purpose, we formed a hypothesis that such a relationship is constitutively polemical, since there is, in this case, the emergence of a constitutive incompatibility. To verify the functioning of the referred relationship, we analyze, in the texts of the data, linguistic signs, that emerge quite regularly and point to a discursive functioning. The results indicate that the polemic established between the two positions studied functions as arguments source both for the Proponent position and for the Opponent, since each one these constitutes its legitimacy based on the disqualification of the other.

Keywords: Interdiscourse. Polemic. Argumentation. Prostitution regulation. 


\section{Introdução}

O projeto de lei Gabriela Leite', proposto em 2012, pelo deputado Jean Wyllys, visa à regulamentação, como profissão, da atividade dos profissionais do sexo ${ }^{2}$, ou seja, da profissionalização da prostituição. A proposta desse projeto suscitou uma série de discussões a respeito do tema. A partir da investigação dos textos que circularam nas mídias digitais acerca da referida proposta, constatamos a emergência de uma relação polêmica que se constitui em torno de dois posicionamentos: os contrários e os favoráveis à referida regulamentação. Partindo dessa constatação inicial, objetivamos, neste artigo, analisar textos que abordam o tema da profissionalização da prostituição. Sendo assim, buscamos verificar a emergência de indícios textuais, bem como de um funcionamento argumentativo, que apontam para existência de uma polêmica constitutiva. Para tanto, recortamos de um corpus mais amplo dois textos que materializam alguns traços da referida polêmica. Os textos selecionados foram: Prostituição: não, não é um trabalho, não é uma profissão! De Tania Navarro Swain $(2013)^{3}$, contrário à regulamentação da prostituição como profissão; e Regulamentar pra quê? (Ou: "Que mais essas prostitutas querem?”), de Monique Prada (2015) ${ }^{4}$, que assume um posicionamento favorável à referida regulamentação.

Como aparato teórico, recorremos ao conceito de polêmica postulado por Maingueneau (2005 [1984]) em Gênese dos Discursos. Além disso, propomos a existência de uma relação teórico-analítica entre o conceito de polêmica postulado por Maingueneau (2005 [1984]) e o conceito de polêmica, como modalidade argumentativa, apresentado por Amossy (2017).

Este artigo está organizado da seguinte forma: em um primeiro momento, apresentamos uma discussão acerca dos principais conceitos

\footnotetext{
${ }^{1}$ Site da Câmara dos Deputados. Disponível em: http://www2.camara.leg.br/. Acesso em: 22 jan. 2018.

${ }^{2}$ Recorremos à expressão "profissionais do sexo" porque essa é a mesma utilizada no projeto de lei Gabriela Leite. Neste artigo, usamos as expressões "profissionalização da prostituição" e "regulamentação da prostituição como profissão" como paráfrases e, portanto, neste trabalho, elas são intercambiáveis.

3 SWAIN, Tania Navarro. Prostituição: não, não é um trabalho, não é uma profissão! Labrys, 2013. Disponível em: http://labrys.net.br/labrys24/prostituion/anahitapt.htm. Acesso em: 19 mai.2019.

${ }^{4}$ PRADA, Monique. Regulamentar pra quê? (Ou: “Que mais essas prostitutas querem?”). Jusbrasil, 2015. Disponível em: https://camilavazvaz.jusbrasil.com.br/noticias/351461905/regulamentar-praque-ou-que-mais-essas-prostitutas-querem. Acesso em: 19 mai.2019.
} 
teórico-metodológicos que fundamentam as análises. Em um segundo momento, procedemos às análises dos dados, com base nos dois textos supracitados, que, como dito, selecionamos de um corpus mais amplo. Por fim, em um terceiro momento, apresentamos a discussão dos resultados, seguida das conclusões a que conseguimos chegar com base nas análises realizadas.

\section{Fundamentos teórico-metodológicos}

Maingueneau (2005 [1984]) propõe, como primeira hipótese de trabalho, a precedência do interdiscurso sobre o discurso. Para ele, a hipótese do primado do interdiscurso inscreve-se na perspectiva de uma heterogeneidade constitutiva, que "amarra, em uma relação inextricável, o mesmo do discurso e seu outro" (MAINGUENEAU, 2005 [1984], p. 33). Reconhece, ainda, que sua hipótese do primado do interdiscurso se inscreve, em alguma medida, na perspectiva bakhtiniana de uma heterogeneidade constitutiva, mas afirma operar em um quadro mais restrito, pois trabalha com "um quadro metodológico e um domínio de validade muito mais precisos" (MAINGUENEAU, 2005 [1984], p. 35).

Por trabalhar, como ele mesmo afirma, em um quadro mais restrito, Maingueneau (2005 [1984]), delimita a existência da tríade: universo, campo e espaço discursivos. O universo discursivo é o termo mais amplo e corresponde ao conjunto de discursos que interagem em uma conjuntura dada, sendo, portanto, inacessível ao analista. O campo discursivo corresponde ao conjunto de discursos "que se encontram em concorrência, delimitando-se reciprocamente em uma região determinada do universo discursivo" (MAINGUENAEU, 2005 [1984], p. 35). Essa noção diz respeito, portanto, a diferentes recortes, os quais "delimitam discursos que possuem a mesma função social, mas divergem sobre o modo pelo qual ela deve ser preenchida" (MAINGUENAEU, 2005 [1984], p. 36). Contudo, ainda segundo Maingueneau (2005 [1984]), não é possível determinar, no campo, todas as modalidades (ou formas) de relação que se dão entre os diferentes discursos. É por isso que surge a necessidade de definir espaços discursivos, pois, nesses espaços, que são construídos pelo analista com base em certos critérios, é possível determinar o tipo de relação que se estabelece entre diferentes 
posicionamentos de um mesmo campo. É com base no estudo de dois posicionamentos que partilham de um mesmo espaço discursivo, o jansenismo e o humanismo devoto, que Maingueneau (2005 [1984]) mostra o funcionamento da polêmica discursiva. Para esse autor, a polêmica é, portanto, uma das formas de dois discursos, que partilham de um mesmo espaço, relacinarem-se.

Em um texto de 2010, Maingueneau volta a tratar do polêmico, caracterizando-o, agora, como um registro. De acordo com o referido autor, o polêmico tem a ver com um registro de tipo comunicacional (assim como ocorre com o "discurso didático", o "discurso de divulgação" e o "discurso cômico") e está associado a um "repertório de traços linguísticos considerados característicos de certa 'violência' verbal” (MAINGUENEAU, 2010, p. 189). O autor salienta que o polêmico pertence aos "gêneros instituídos" e não à conversação. Desse ponto de vista, polêmica é um termo que deve ser usado em relação a "conflitos nos quais as questões estão situadas além dos indivíduos que interagem” (MAINGUENEAU, 2010, p. 190). No texto em questão, o autor trata de três dimensões do registro polêmico, as quais permitem compreender a funcionalidade desse tipo de registro.

A primeira delas é a dimensão enunciativo-pragmática. Esta é a dimensão mais imediata do discurso polêmico e indica uma relação de equilíbrio entre o plano linguístico e o pragmático. Desse modo, na análise, enfatiza-se "não somente as marcas enunciativas, mas também a força ilocucional da enunciação [...]" (MAINGUENEAU, 2010, p. 190).

A segunda dimensão é a sociogenérica, que considera as práticas discursivas situadas em um tempo e em um lugar, como espaço privilegiado para se estudar o polêmico, e permite, ainda, relacionar o texto analisado com outros textos que, juntamente com ele, produzem sentido. Ainda segundo Maingueneau, existe um vínculo entre a dimensão sociogenérica e a noção de acontecimento enunciativo. O acontecimento enunciativo do qual trata Maingueneau engloba tanto o quadro comunicacional quanto o gênero do discurso no qual o texto polêmico se insere; e é considerado dentro de uma temporalidade específica.

A terceira dimensão é a semântica. Esta dimensão, de acordo com Maingueneau (2010), mostra-se menos evidente, pois está relacionada à 
localização da identidade semântica dos discursos envolvidos na polêmica, "ligando a interação polêmica ao funcionamento do campo discursivo do qual participam os posicionamentos em conflito" (MAINGUENEAU, 2010, p. 195). Nesse sentido, para que a polêmica se estabeleça, é necessário que a fronteira pela qual se define uma certa identidade discursiva seja ameaçada, ou seja, é preciso que sujeitos que ocupam certo lugar julguem como inaceitáveis os enunciados de outro e decidam pelo conflito com a suposta fonte desses enunciados. E só é possível analisar tal dinâmica quando se consegue identificar a fronteira constitutiva da identidade discursiva de cada posicionamento e, ao mesmo tempo, verificar como os discursos interagem a partir de uma relação entre um interior e um exterior enunciativo, de modo a construir, cada um deles, a sua identidade. Por isso mesmo, o constante confronto entre "discurso agente" (aquele que se encontra na condição de tradutor) e "discurso paciente" (aquele que se encontra na condição de traduzido) se materializa sob a forma de um simulacro, o qual é "construído sob medida pelo discurso que o incorpora para desqualificá-lo" (MAINGUENEAU, 2010, p 196).

Com base em outra perspectiva teórica, Ruth Amossy (2017) define a polêmica como uma modalidade argumentativa. Para tanto, a autora adota uma concepção modular da argumentação, definindo-a como um "continuum que vai da coconstrução das respostas ao choque de teses antagônicas" (AMOSSY, 2017, p. 52). Ainda com base na noção de polêmica como modalidade argumentativa, Amossy (2017) defende que há certos traços que conferem à polêmica sua especificidade no interior do campo da argumentação retórica. Esses traços são a dicotomização, a polarização e a desqualificação do outro. E, de forma secundária, a violência verbal e o pathos. Ainda segundo Amossy (2017), o pathos diz respeito à capacidade de despertar emoções no auditório e é apresentado por Aristóteles, o qual confere, tanto ao pathos quanto ao ethos - a imagem de si do orador, lugar de destaque, quando estuda as formas de persuasão.

Os traços acima apresentados consistem, ainda segundo Amossy (2017, p. 52), numa "ancoragem conflitual” que dá sustentação à polêmica. As análises realizadas pela referida autora centram-se, como dito, numa perspectiva argumentativa da linguagem e, por isso mesmo, supõem uma “estrutura actancial que envolve um Proponente e um Oponente em face de 
um Terceiro" (AMOSSY, 2017, p. 56). Como afirma a própria autora, tal estrutura não diz respeito a pessoas, mas a papéis. Tanto a noção de estrutura actancial quanto a definição de "papel de polemista" às quais Amossy (2017) recorre são apresentadas por Cristian Plantin em seus trabalhos sobre argumentação. De acordo com o referido autor, que é citado por Amossy, "em certos contextos de debates, a pessoa só existe em função de seu papel” (PLANTIN, 2003, p. 386 apud AMOSSY, 2017, p. 58)

$\mathrm{Na}$ estrutura actancial, os participantes mais diversos se juntam em dois grupos antagônicos, os quais fazem parte de categorias sociais diversas e materializam uma grande variedade de "vozes que se fazem ouvir na sua diversidade" (AMOSSY, 2017, p. 57). Ainda segundo a autora, tal polarização pode, algumas vezes, se sustentar em identidades pré-formadas, como é o caso, por exemplo, dos lugares ideológicos estudados pela AD clássica, mas "não segue necessariamente linhas de divisão preexistentes e pode reconfigurar os grupos em torno de bandeiras que clamam ao agrupamento" (AMOSSY, 2017, p. 57).

A perspectiva defendida por Plantin (2003), Amossy (2017), entre outros (conferir nota 5), segundo a qual actantes assumem papéis no interior de uma polêmica, não coaduna com a noção de Formação Discursiva com base na qual Maingueneau (2005 [1984]) realiza suas análises dos discursos devotos, pois, no momento em que analisa tais discursos (entre o final da década e 1970 e o início da década de 1980), o autor ainda está bastante vinculado ao quadro teórico que constitui aquilo que, posteriormente, Pêcheux (1993 [1983]) define como segunda fase da Análise de Discurso, ou AD-2. Por isso, Maingueneau (2005 [1984]) recorre à noção de Formação Discursiva. Contudo, o próprio Maingueneau, no prefácio da edição brasileira de Gênese dos discursos, reconhece que atualmente "falaria preferencialmente de 'posicionamento"' (MAINGUENEAU, 2005, p. 12).

Além disso, como dito anteriormente, mais recentemente, Maingueneau (2010) mostra que os posicionamentos envolvidos em uma polêmica fazem

\footnotetext{
${ }^{5}$ Para mais detalhes acerca dos trabalhos de Plantin sobre argumentação e polêmica, indicamos: PLANTIN, Christian. Deixem dizer: a norma do discurso de um está no discurso do outro. Comunicação e Sociedade, vol. 16, 2009, pág. 145-161; PLANTIN, Christian. Análise e crítica do discurso argumentativo. Tradução: Rodrigo dos S. Mota, Sébastien G. Giancola; Thaise A. dos Santos. Revisão da tradução: Moisés Olímpio-Ferreira; Sérgio I. Levemfous. EID\&A - Revista Eletrônica de Estudos Integrados em Discurso e Argumentação, n. 1, p. 17-37, nov. 2011.
} 
parte do “"dispositivo' pragmático por meio do qual as marcas enunciativas da polêmica adquirem sentido" (MAINGUENEAU, 2010, p. 191). Por isso, apesar de a noção de posicionamento não corresponder exatamente ao conceito de actantes de Amossy (2017), os quais, segundo a referida autora, "assumem o papel de Proponente e de Oponente" no interior de uma "estrutura actancial" (AMOSSY, 2017, p. 57), defendemos aqui que existe uma relação entre tais noções. Afinal, tanto o dispositivo pragmático quanto a estrutura actancial permitem-nos considerar "certa encenação da atividade discursiva" (MAINGUENEAU, 2010, p. 190). Trata-se, segundo Maingueneau (2010), “de pensar uma relação entre lugares, papéis, normas..." (MAINGUENEAU, 2010, p. 192). Portanto, o que nos interessa no texto de Amossy (2017) é a hipótese segundo a qual a polêmica "surge como um modo particular de gestão do conflito" (AMOSSY, 2017, p. 53), que, como dissemos, funciona com base em três aspectos (ou traços): i) a dicotomização, segundo a qual duas posições antitéticas se excluem mutuamente; ii) a polarização, que consiste em estabelecer campos inimigos (Proponente e Oponente); e iii) a desqualificação do outro, pois, devido a essa desqualificação, esse outro, como defende Maingueneau (2005 [1984], só pode existir, no interior do discurso do adversário, como simulacro que este adversário (ou Oponente) constrói dele.

No próximo tópico, apresentamos as análises dos dados, que serão feitas com base nos conceitos propostos por Maingueneau (2005 [1984]; 2010) e por Amossy (2017).

\section{Análises dos dados}

Nesta seção, apresentamos as análises feitas a partir dos pressupostos teóricos já explicitados. Os textos aos quais recorremos, como dito, fazem parte de um corpus mais amplo, composto por textos que abordam o tema da regulamentação da prostituição.

Ao tratar da hipótese da semântica global, Maingueneau (2005 [1984]) defende que todas as dimensões da discursividade estão sujeitas ao mesmo sistema de restrições globais. Esse sistema estabelece as condições de enunciabilidade de um discurso. Nessa perspectiva, propomos que o Projeto de Lei Gabriela Leite (2012), apresentado pelo então deputado federal Jean Willys, foi, no Brasil, o acontecimento que favoreceu certa enunciabilidade de 
discursos que tratam da regulamentação da prostituição. Dessa forma, a emergência do referido projeto de lei constitui um dos elementos daquilo que Maingueneau (2010) chama de dimensão sociogenérica, conforme a explicitamos no tópico anterior.

Nos textos aqui apresentados, realizamos uma análise interdiscursiva por meio da qual identificamos alguns indícios que emergem com certa regularidade. Tais indícios apontam, como veremos, para o funcionamento de uma polêmica discursiva.

\subsection{Discurso agente / Oponente}

Nos textos selecionados, constatamos que o discurso contrário à regulamentação da prostutição é o que assume o papel de discurso agente. Em Prostituição: não, não é um trabalho, não é uma profissão!, de Tania Navarro Swain (2013), há, já no título, uma negação polêmica que marca, de forma veemente, o posicionamento contrário à regulamentação da prostituição. Ainda em relação ao título, vemos que o termo "prostituição", devido aos dois pontos, aparece destacado do restante do enunciado. Além disso, o advérbio de negação não é repetido três vezes, o que confere ao título um tom categórico e enfático. Nessa perspectiva, o referido título funciona como uma possível resposta a um dos principais argumentos do discurso favorável à regulamentação da prostituição, que aqui estamos apresentando como discurso paciente. Esse posiciomaneto favorável à profissinalização da prostituição defende que a esta é um trabalho como outro qualquer e, por isso, deve ser reconhecida legalmente como profissão. Outros indícios de que o discurso contrário à regulamentação da prostituição é o discurso agente são os simulacros, ou seja, as "traduções", como postula Maingueneau (2005 [1984]), que o discurso agente faz, com base em sua grade semântica específica, do seu Outro, que é o discurso paciente. Esses simulacros se materializam no texto sob análise por meio de expressões utilizadas para se referir ao discurso paciente. A esse respeito, vejamos o seguinte excerto:

Excerto 1:

A imagem da mulher em estado de prostituição derrama-se sobre todas as mulheres como corpos disponíveis ao desejo sexual [...] Assim, a venda de mulheres com fins sexuais é construída historicamente (SWAIN, 2013, grifamos). 
No excerto 1, os trechos em destaques são simulacros que o discurso agente faz do discurso paciente. Nesse caso, a "tradução" ocorre pela forma de nomear as prostitutas, apresentadas como "mulheres em estado de prostituição", o que indica que não se trata de uma condição inerente à mulher, mas de uma situação, um estado. Trata-se, ainda segundo indica a nomeação, de algo transitório e também da ordem da passividade. Portanto, não pode ser visto como uma profissão. Isso porque, devido à dimensão sociogenérica, considera-se que uma profissão não é algo transitório (não existem pessoas em estado de médico ou estado de engenheiro ou ainda de professor) e também não é algo que é imputado a outrem. As pessoas, costumeiramente, escolhem uma profissão e não simplesmente a aceitam. Porém, quando se diz que alguém está em "estado de fome" ou em "estado de pobreza", supõe-se que essa condição não foi escolha do indivíduo, mas foi algo que lhe foi imputado por condições alheias à sua vontade. Nesse sentido, referir-se às mulheres "em estado de prostituição" é, semanticamente, polemizar com o discurso paciente, o qual defende que a prostituição é uma profissão. Também temos, no excerto acima, a tradução do termo "prostituição", que é nomeado como "venda de mulheres com fins sexuais". Aqui, a troca de um substantivo que indica uma atividade exercida por sujeitos - prostituição como a atividade realizada por pessoas que se prostituem -, por uma expressão que funciona como uma espécie de definição do referido substantivo - prostituição: venda de mulheres com fins sexuais - funciona como um simulacro do discurso paciente, justamente porque define o Outro com base nas categorias semânticas do Mesmo que, nesse caso, é o Oponente e que, portanto, busca destruir o Proponente, segundo a conceituação proposta por Amossy (2017). Constatamos, no primeiro exemplo, que o discurso contrário à regulamentação da prostituição constrói simulacros, por meio de expressões referenciais, do discurso favorável à referida regulamentação. Esse fenômeno de "tradução" vincula-se, segundo Maingueneau (2005 [1984]), a um processo de interincompreensão regrada, em que, ainda segundo o autor, um posicionamento discursivo só pode interpretar seu Outro por meio dos simulacros que constrói dele. Contudo, como já mencionado, as marcas enunciativas de uma polêmica discursiva também podem ser identificadas no plano linguístico, como vimos no caso da negação polêmica presente no título do texto sob análise. 
Do ponto de vista das estratégias argumentativas, o texto se inicia com duas perguntas retóricas ${ }^{6}$ : "A quem interessa a manutenção da prostituição com uma fachada legal, transformada em uma 'profissão'? A quem interessa, de fato, a existência de corpos disponíveis à compra e à venda, em um mercado em expansão?" (SWAIN, 2013). Tais questionamentos marcam a relação conflitual entre dois adversários: defensores da regulamentação da prostituição como profissão e contrários à referida regulamentação. Esses últimos, que consideram tal regulamentação como "uma fachada legal, transformada em uma 'profissão", são aqueles cujo ponto de vista o texto acima citado corrobora. Para Amossy (2017), o conflito situa-se no centro da polêmica. Nesse sentido, iniciar o texto com perguntas retóricas que ratificam o conflito é uma forma de marcar a dicotomização que, ainda segundo Amossy (2017), "torna problemática a busca por um acordo" (AMOSSY, 2017, p. 55). Em relação especificamente ao excerto 1, que corresponde ao sétimo parágrafo do texto sob análise, ele retoma uma expressão referencial "mulher em estado de prostituição" - que é utilizada desde o segundo parágrafo do texto. Essa forma de nomeação ratifica a construção de uma dicotomização entre aqueles que são favoráveis à regulamentação da prostituição como profissão e aqueles que, assim como o enunciador do texto, mostram-se contrários à referida regulamentação. Isso porque, essa forma de nomear marca uma diferença constitutiva entre esses dois polos da polêmica: não se trata de "profissionais do sexo", como define o Proponente, mas de "mulheres em estado de prostituição", como defende o Oponente. Conforme propõe Amossy (2018), essa polarização entre Proponente e Oponente "se cria além, e apesar, de numerosas divergências" (AMOSSY, 2017, p. 57). No caso da polêmica em torno da regulamentação da prostituição como profissão, há feministas que defendem que a prostituição deve ser regulamentada, mas há também feministas que condenam tal regulamentação. Contudo, independentemente do lugar social que assumem, aqueles que são contrários à regulamentação da prostituição como profissão se constituem, textual e discursivamente, como Oponentes dos que são favoráveis à regulamentação da referida atividade. E uma das formas de

\footnotetext{
${ }^{6}$ De acordo com Bakhtin/Volochinov (2002 [1929]), perguntas retóricas são aquelas que se situam, de alguma maneira, na fronteira entre o discurso citante e o discurso citado. Assim, "podem ser interpretadas como uma pergunta da parte do autor, mas também como uma pergunta de um personagem" (BAKHTIN/VOLOCHINOV, 2002 [1929], p. 170).
} 
marcar essa oposição é por meio das nomeações: mulheres em estado de prostituição vs profissionais do sexo; ou "profissão" vs profissão. Nesse último caso, as aspas de distanciamento ${ }^{7}$ indicam que o Oponente não concorda com a nomeação do Proponente.

Vejamos outro exemplo de funcionamento da polêmica:

\section{Excerto 2}

Que liberdade é esta, das mulheres em estado de prostituição? Seus corpos não tem mais integridade, são decompostas em partes mais ou menos desejáveis; seu psiquismo não existe, tudo se passa como se estas mulheres estivessem ausentes de sua materialidade para suportar a invasão de seus corpos.

Esta "liberdade" de escolha pode - tudo é possível - ser exercida por mulheres, extremamente raras, que consentem em ser tratadas como dejetos ou vasos sanitários Ou que apenas afirmam sua escolha e desejam a denominação "profissão" para criar um semblante da dignidade, que lhes é negada no simbólico na materialidade social (SWAIN, 2013, grifamos).

No excerto 2, que corresponde aos dois últimos parágrafos do texto sob análise, vemos, mais uma vez, uma pergunta retórica iniciando tema apresentado nos dois parágrafos acima transcritos. Nesse caso, o tema é a suposta liberdade da mulher de fazer o que quer com seu corpo. Segundo o discurso agente, cujo ponto de vista encontra-se materializado no excerto acima, essa suposta liberdade é um dos argumentados utilizado pelos defensores da regulamentação da prostituição como profissão para defender a referida regulamentação. O excerto apresenta o argumento do discurso paciente em forma de pergunta retórica, para, em seguida, desqualificá-lo. Essa desqualificação do Outro é um dos aspectos da polêmica como modalidade argumentativa, conforme defende Amossy (2017).

Tal desqualificação se mostra na resposta dada à pergunta retórica, pois todos os argumentos apresentados indicam que não há liberdade, mas o que há, ao contrário do que defende o discurso paciente, é uma espécie de perda da liberdade, já que a mulher em estado de prostituição perde a integridade de seu corpo ("seus corpos não tem mais integridade, são decompostas em partes mais ou menos desejáveis"); e de seu psiquismo ("seu psiquismo não

\footnotetext{
${ }^{7}$ Sobre aspas de distanciamento, Authier-Revuz (2004), afirma que “[...], pode-se considerar essas palavras aspeadas como 'mantidas à distância', em um primeiro sentido, como se mantém afastado um objeto que se olha e que se mostra" (AUTHIER-REVUZ, 2004, p. 218).
} 
existe [...]"). Dessa forma, por meio de uma estratégia argumentativa, que consiste na desqualificação de um dos principais argumentos que fundamenta a tese de seu adversário, o Oponente desqualifica o Proponente. Além disso, no parágrafo subsequente, essa desqualificação do outro se materializa na desqualificação das mulheres que consideram a prostituição como um exercício de liberdade. Essas mulheres são apresentadas como extremamente raras e são desqualificadas por meio de expressões consideradas, pelo senso comum, como inadequadas e ofensivas. Nesse caso, o Oponente interpreta a atividade realizada pelas prostitutas como algo semelhante a consentir em serem "tratadas como dejetos ou vasos sanitários". Aqui, há tanto o que Maingueneau (2005 [1984]) chama de simulacro, pois a atividade sexual é "traduzida" por meio do enunciado serem "tratadas como dejetos ou vasos sanitários", quanto o que o próprio Maingueneau (2005 [1984]) e também Amossy (2017) definem como violência verbal. Isso porque, de acordo com a dimensão sociogenérica, os termos utilizados no referido enunciado têm, além do tom agressivo, certa veemência, que se marca tanto pela expressão "tudo é possível" (que antecede o enunciado "ser exercida por mulheres, extremamente raras, que consentem em ser tratadas como dejetos ou vasos sanitários") $)^{8}$ quanto pela escolha lexical de expressões que são, como dito, consideradas inadequadas e ofensivas. Contudo, é importante destacar que, para Amossy (2017), “nem toda violência verbal [...] é polêmica. Os procedimentos discursivos que criam uma impressão de violência verbal só se tornam polêmicos quando são utilizados no contexto de uma confrontação de opiniões contraditórias" (AMOSSY, 2017, p. 63). Conforme o que estamos defendendo neste artigo, no caso da polêmica em torno da regulamentação da prostituição como profissão, há uma confrontação de opiniões contraditórias. E, portanto, há polêmica.

Ainda no excerto 2, vemos, novamente, o uso das aspas de proteção, tanto em "liberdade" quanto em "profissão". Nesses dois casos, assim como mostramos no excerto 1 , o enunciador recorre às aspas para indicar que não concorda com as nomeações utilizadas, ao mesmo tempo em que indica que tais nomeações fazem parte do discurso de seu adversário, pois é este que

\footnotetext{
${ }^{8}$ Nesse caso, a expressão "tudo é possível" indica que, segundo o ponto de vista do enunciador, a mulher consentir ser tratada como dejeto ou vaso sanitário é algo absurdo.
} 
considera que a prostituição é tanto um exercício de liberdade quanto uma profissão.

A desqualificação do argumento segundo o qual a prostituição é uma forma de a mulher exercer sua liberdade é também realizada em outro momento do texto, mais precisamente, no quinto parágrafo, abaixo transcrito:

\section{Excerto 3}

Há uma proposição simplista, ingênua ou de má fé que apresenta a prostituição como resultado de uma escolha, de um exercício de liberdade. Apaga-se assim todo o mecanismo de exploração e redução das mulheres a seus corpos, cavidades a serem preenchidas pelo assujeitamento ou pela força. Assim desaparece toda uma literatura feminista que analisa os aspectos materiais e simbólicos do "direito" dado aos homens de possuir e transformar as mulheres em objeto de desfrute (SWAIN, 2013, grifamos).

Nesse caso, o argumento da liberdade é rebatido por meio de expressões bastante enfáticas e que, mesmo não sendo consideradas de baixo calão, como no caso anteriormente analisado, também indicam a presença de certa violência verbal, pois reduzem e ofendem o adversário, ao acusá-lo de elaborar uma proposição "simplista, ingênua ou de má fé". Além disso, há, mais uma vez, a construção de um simulacro do discurso do adversário, pois esse é acusado de considerar os corpos das mulheres como "cavidades a serem preenchidas pelo assujeitamento ou pela força". No segundo período do excerto, o termo "exploração" e a expressão "redução das mulheres a seus corpos" são apresentados como processos implícitos à prostituição. Nessa perspectiva, o argumento de que a prostituição como profissão é fruto de uma livre escolha, como defende o posicionamento favorável à regulamentação da prostituição, é, de certa forma, rebatido, sob a acusação de não considerar a "exploração sexual" nem a "redução das mulheres a seus corpos". Nesse terceiro excerto, constatamos, ainda, que, para o discurso materializado no texto sob análise, o feminismo funciona como o terceiro espectador (MAINGUENEAU, 2010). Para Maingueneau, o terceiro espectador é "frequentemente, considerado como alguém que assume as normas subjacentes ao debate" (MAINGUENEAU, 2010, p. 192). No excerto, o feminismo é apresentado como fornecedor de toda uma literatura que "analisa os aspectos materiais e simbólicos do 'direito' dado aos homens 
de possuir e transformar as mulheres em objeto de desfrute". Aqui, há, mais uma vez, o recurso às aspas de proteção. Nesse caso, o enunciador indica que seu adversário considera a prostituição como um direito dos homens de possuir e transformar as mulheres em objeto de desfrute, mas o enunciador do texto sob análise não concorda com tal nomeação, pois, para ele, não se trata de um direito. Identificamos, assim, mais um simulacro de prostituição, pois essa é apresentada, no enunciado acima, como um "direito dado aos homens de possuir e transformar as mulheres em objeto de desfrute".

Com base nas análises apresentadas até aqui, constatamos o funcionamento da relação polêmica entre contrários e favoráveis à regulamentação da prostituição como profissão, observando, mais especificamente, o posicionamento contrário, já que este exerce o papel de discurso agente.

Veremos, agora, o funcionamento do discurso paciente ou do Proponente, que é favorável à regulamentação da prostituição como profissão.

\subsection{Discurso paciente / Proponente}

O discurso favorável à regulamentação da prostituição como profissão é caracterizado como discurso paciente, pois é traduzido pelo discurso contrário à referida regulamentação. É necessário ressaltar que Maingueneau (2005 [1984]) afirma que as definições de discurso agente e de discurso paciente, na relação polêmica, são intercambiáveis.

No texto selecionado para este artigo, cujo título é Regulamentar pra quê? (Ou: “Que mais essas prostitutas querem?”), assinado por Monique Prada (2015), constatamos, assim como no texto anterior, aspectos que apontam para existência de uma polêmica discursiva. A esse respeito, vejamos, inicialmente, o excerto abaixo:

\section{Excerto 4:}

Papo vai, papo vem e o assunto é "PUTA". Citadas a torto e a direito em mesas de debates [...] na roda feminista ou mesmo em locais nem tão honrosos assim (como a boca de pastores e religiosos em geral, por exemplo), fato é que desde que a questão da regulamentação do trabalho sexual voltou à pauta [...] não mais tivemos paz. Gente que até noites antes de o PL 4211/2012 ser apresentado 
não queria nem ouvir falar de nós agora vive com a puta na boca [...] a regulamentação nos traz não apenas segurança financeira como proteção contra assédio e outros tipos de violência (PRADA, 2015, grifamos).

O excerto 4, que corresponde ao primeiro parágrafo do texto sob análise, indica que um dos argumentos centrais para estabelecer a polarização entre contrários e favoráveis à regulamentação da prostituição é o de autoridade. Trata-se de mostrar quem pode, porque entende, e quem não pode, porque não o conhece profundamente, tratar do tema. Nesse sentido, o trecho "Gente que até noites antes de o PL 4211/2012 ser apresentado não queria nem ouvir falar de nós agora vive com a puta na boca" materializa um discurso que desqualifica os argumentos de muitos que opinam sobre a regulamentação da prostituição, com base no contra-argumento de que eles não conhecem nada sobre o referido tema. Essa desqualificação é materializada quando o enunciador afirma que o tema da regulamentação da prostituição é tratado em "roda feminista ou mesmo em locais nem tão honrosos assim (como a boca de pastores e religiosos em geral, por exemplo)". Nesse caso, o enunciador indica, por um lado, que nem todas as rodas feministas podem tratar do tema da prostituição, apesar de esse mesmo enunciador reconhecer que as ditas rodas feministas são locais honrosos. Por outro lado, há uma desqualificação ainda maior dos pastores e religiosos em geral que tentam tratar do tema da regulamentação da prostituição, pois esses são apresentados não só como não conhecedores do tema, mas também como "locais nem tão honrosos", quando comparados às rodas feministas. Vemos aqui tanto a dicotomização, que se dá pelo distanciamento estabelecido entre contrários e favoráveis, quanto a polarização, pois apesar de indicar que existem contrários mais ou menos respeitáveis, o que os diferencia em certa medida, o enunciador do texto defende que nem o mais respeitável (roda feminista) nem o menos (pastores e religiosos em geral) pode, de fato, tratar do tema, pois não o conhecem em sua profundidade. Essa polarização fica ainda mais forte quando o enunciador se identifica como sendo ele mesmo uma prostituta: “Então - e não que a minha palavra seja de grande valia neste debate (como prostituta, incrivelmente faço parte do grupo de pessoas cuja opinião menos pesa nesta questão...)” (PRADA, 2015). Nesse caso, mesmo quando afirma que sua opinião não é "de grande valia neste debate", o enunciador se distancia daqueles outros que querem dar um 
"pitacozinho"9 no debate sobre a regulamentação da prostituição como profissão. Aqui (e em outros momentos do texto), o enunciador se marca como um nós ("tivemos paz”, "queria nem ouvir falar de nós”, "nos traz não apenas [...]") que pode tratar do tema, porque, ao contrário do seu adversário no espaço discursivo, conhece o mesmo, uma vez que está implicado nele.

Ainda no excerto 4, o trecho "a regulamentação nos traz não apenas segurança financeira como proteção contra assédio e outros tipos de violência" indica que a regulamentação da prostituição é benéfica. Esse trecho funciona como uma negação ao argumento do posicionamento contrário, o qual defende, como vimos no primeiro texto analisado, que a prostituição é uma forma de exploração das mulheres.

No texto, também há simulacros. A esse respeito, vejamos o seguinte excerto:

Excerto 5:

[...] e já aviso que a leitura somente será proveitosa se trabalho sexual pra ti é trabalho, e não algo a ser eliminado da face da Terra. Aqui lidamos sempre com o conceito de que trabalho sexual É trabalho (PRADA, 2015, grifamos).

No excerto 5, o trecho "e já aviso que a leitura somente será proveitosa se trabalho sexual pra ti é trabalho, e não algo a ser eliminado da face da Terra" apresenta um simulacro do discurso adversário, pois indica, por meio de um negação polêmica, que o Oponente considera o trabalho sexual como algo que "deve ser eliminado da face da terra", o que é ratificado pela expressão "trabalho sexual É trabalho", que também polemiza com o Oponente, quando este afirma que a prostituição (lida pelo discurso Proponente como "trabalho sexual") não é trabalho.

Para finalizar as análises, vejamos um último excerto, que corresponde à conclusão do texto Regulamentar pra quê? (Ou: "Que mais essas prostitutas querem?") (PRADA, 2015):

Excerto 6:

Em resumo e na prática, as coisas para nosso lado vão, como de costume, de mal a pior. Com o PL 4211/2012 rejeitado, um Congresso cada vez mais conservador e

\footnotetext{
${ }^{9}$ Termo utilizado no próprio texto: "toda e todo cidadã brasileira e cidadão brasileiro hoje tem um pitacozinho pra dar sobre a vida das mundanas".
} 
autoritário e cheio de demandas mais urgentes, vamos ficando de lado. Some-se a isso a perda de Gabriela Leite e a (as colegas que me desculpem, mas...) nítida dificuldade ou mesmo incapacidade do movimento de apoiar e empoderar outras lideranças à altura de Gabriela, mais o pânico moral de um Governo que segue nos vendo apenas da cintura pra baixo e as esperanças são parcas... Sigamos (PRADA, 2015, grifamos).

O excerto acima, vemos a retomada da dicotomização, que, mais uma vez, materializa-se pela oposição entre um "nós", no qual a enunciadora do texto se inclui, e um "eles", que, nesse último parágrafo, é marcado pelo Congresso, categorizado como "cada vez mais conservador", e pelo Governo que, segundo o excerto em tela, "segue nos vendo apenas da cintura pra baixo", em que "nos" refere-se às prostitutas, entre as quais, como dito, a enunciadora se inclui. Há, também nesse excerto, uma desqualificação do outro, pois o Congresso é apresentado como "cada vez mais conservador", o que, considerando a dimensão sociogenérica, é algo negativo, já que o texto é de 2015, quando o Brasil estava sob a égide de um governo que se dizia progressista; e o Governo é definido, também no texto sob análise, como um governo "que segue nos vendo (as prostitutas) apenas da cintura pra baixo", o que indica que o governo só enxergava a mulher pela sua sexualidade, daí a metonímia "da cintura para baixo". Tal afirmação é também uma desqualificação porque o governo da presidente Dilma Rousseff, que era a presidente do Brasil em 2015, se autoproclamava progressista e de esquerda, não podendo, portanto, ser visto como machista ou misógino, características atribuídas a quem enxerga a mulher pela sua sexualidade, ou seja, "da cintura para baixo”. Nesse caso, a desqualificação do adversário só pode ser verificada se a considerarmos para além da dimensão enunciativo-discursiva, que corresponde, conforme Maingueneau (2010), ao que é dito a partir de certas condições de enunciabilidade, e também a dimensão sociogenérica, que diz respeito às condições histórico-sociais sob as quais as polêmicas se desenrolam.

Em síntese, as análises indicam que há, de fato, uma polêmica, como postulada por Maingueneau (2005 [1984]), entre os posicionamentos contrários e favoráveis à regulamentação da prostituição como profissão. Trata-se, para usar as palavras de Amossy (2017), de um modo de gestão do conflitual que se dá com base em uma dicotomização entre Proponente, os 
que defendem a regulamentação da profissionalização da prostituição; e Oponente, os que são contrários à referida regulamentação.

\section{Considerações finais}

Os resultados indicam que os textos aqui analisados, que tratam da regulamentação da prostituição como profissão, fazem eco a outros textos que materializam uma relação que se constitui e se delineia dentro de um mesmo espaço discursivo. No interior desse espaço, a relação que se estabelece entre favoráveis e contrários à referida regulamentação mostra-se constitutivamente polêmica. Tal polêmica se materializa por meio de marcas linguísticas, como, por exemplo, a negação polêmica e as perguntas retóricas, mas também por meio de uma cena que se constitui a partir de uma dimensão sociogenérica, a qual define os lugares do Proponente e do Oponente. E, finalmente, por meio de certo funcionamento semântico, marcado por uma interincompreensão regrada, que tem, como uma de suas marcas, a construção de simulacros, pois, dentro desse espaço discursivo polêmico, o Mesmo só pode relacionar-se com o Outro por meio do simulacro que constrói deste.

Além disso, as análises mostraram que é possível articular conceitos da polêmica discursiva, conforme proposta por Maingueneau (2005 [1984]; 2010), e noções da polêmica como modalidade argumentativa, tal qual apresentada no trabalho de Amossy (2017), apesar de esses dois autores não se fundamentarem nos mesmos princípios teóricos. Tal aproximação, guardadas as devidas especificidades, só é possível porque a polêmica estabelecida entre os dois posicionamentos estudados funciona como fonte de argumentos tanto para o Proponente quanto para o Oponente, já que cada um deles constitui sua legitimidade com base na desqualificação do outro, o que reforça tanto a tese da polêmica constitutiva de Maingueneau (2005 [1984]) quanto a tese da polêmica como um modo de gestão de conflitos, como propõe Amossy (2017). 


\section{Referências}

AMOSSY, Ruth. Apologia da polêmica. Tradução: Rosalice Botelho Pinto et al. São Paulo: Contexto, 2017.

AUTHIER-REVUZ, Jacqueline. Palavras mantidas à distância. In: Entre a transparência e a opacidade: um estudo enunciativo do sentido. Tradução: Heloisa Monteiro Rosário. Porto Alegre: EDIPUCRS, 2004. p. 217-237.

BAKHTIN, Mikhail (VOLOCHINOV). Marxismo e filosofia da linguagem. Tradução: Michel Lahud e Yara Frateschi Vieira. São Paulo: Hucitec; Annablume, 2002 [1929].

MAINGUENEAU, Dominique. Gênese dos discursos. Tradução: Sírio Possenti. Curitiba: Criar Edições, 2005 [1984].

MAINGUENEAU, Dominique. Prefácio do autor. In: Tradução: Sírio Possenti. Curitiba: Criar Edições, 2005 [1984]. p. 11-14. . Gênese dos discursos.

MAINGUENEAU, Dominique. Registro: as três facetas do polêmico. Tradução: Sírio Possenti. In: Doze conceitos em Análise do Discurso. Organização: Sírio Possenti e Maria Cecília Perez de Souza-e-Silva. São Paulo: Parábola Editorial, 2010. p. 171-186.

PÊCHEUX, Michel. Análise do Discurso: três épocas. Tradução: Jonas Romualdo. In: GADET, Françoise; HAK, Tony (Org.). Por uma análise automática do discurso: uma introdução à obra de Michel Pêcheux. Campinas, Ed.UNICAMP, 1993 [1983].

\section{Forma de citação sugerida}

SILVA, Edvania Gomes da; PIRES, Lara Maria dos Santos. Regulamentação da prostituição: polêmica e argumentação. EID\&A - Revista Eletrônica de Estudos Integrados em Discurso e Argumentação, Ilhéus, n. 19, p. 28-46, ago.2019. DOI dx.doi.org/10.17648/eidea-19-2395. 